\title{
Osteotendinous Suturing for Anchorage of Medial Arthrotomy in Total Knee Arthroplasty
}

\author{
Sanjay Agarwala, Lokesh Sharoff, Sameer Chaudhari \\ Department of Orthoapedic Surgery, P.D. Hinduja National Hospital \& Medical Research Centre, Mumbai, India \\ Email: drsa2011@gmail.com, drlokeshsharoff@outlook.com, sameertch84@gmail.com
}

How to cite this paper: Agarwala, S., Sharoff, L. and Chaudhari, S. (2016) Osteotendinous Suturing for Anchorage of Medial Arthrotomy in Total Knee Arthroplasty. Open Journal of Orthopedics, 6, 357-362. http://dx.doi.org/10.4236/ojo.2016.612048

Received: November 9, 2016

Accepted: December 12, 2016

Published: December 15, 2016

Copyright $\odot 2016$ by authors and Scientific Research Publishing Inc. This work is licensed under the Creative Commons Attribution International License (CC BY 4.0).

http://creativecommons.org/licenses/by/4.0/

\section{Abstract}

Aim: To develop a method for closure of the arthrotomy wound and approximation of the medial periosteum at the level of tibial tuberosity after total knee arthroplasty in severe varus deformity. Method: We describe a technique of osteotendinous suturing through the tibial tuberosity for suturing of the medially elevated periosteum. Result: This is an easily reproducible technique which results in very early mobilisation and no additional complications and has several advantages over other methods of closure. Conclusion: The osteotendinous technique can be used for medial arthrotomy closure after correction of severe varus deformities and also after partial patellar tendon avulsions in total knee arthroplasty surgeries.

\section{Keywords}

Total Knee Replacement, Anchor, Patellar Tendon Avulsion, Bone Tunnel, Patellar Tendon Suturing, Transosseous

\section{Introduction}

Approximately 700,000 Total Knee Arthroplasty (TKA) procedures are performed annually in the US. By 2030, this number is expected to increase to 3.48 million per year [1]. In India, majority of the patients are undergoing TKA present at an advanced stage with a severe varus deformity. The success of a TKA depends on various factors which include appropriate choice of implant and meticulous surgical technique, one of which is closure of the arthrotomy. Anatomical and watertight arthrotomy closure reduces the dead space, and provides a tamponade effect thus reducing the hematoma formation [2]. Cases which have severe varus deformity, the medial soft tissue structures are contracted and shortened. The extended medial periosteal sleeve elevation has to be done in order to correct this deformity. After correction of this deformity in a TKA, there is a 
huge gap left between the incised soft tissues. The approximation of the periosteal sleeve with the patellar tendon becomes difficult and the sutures cut through the tissues if approximated forcefully. Various techniques can be used like metal clips or suture anchors for approximation of these structures. But these are expensive and have various disadvantages of infection.

We describe a technique of drilling holes into the tibial tuberosity to achieve better approximation and preventing cut through of sutures through the tissues.

\section{Surgical Technique}

The senior author performed and used this technique in 655 total knee arthroplasties done in 36 months and the steps were the same in all the cases. 212 knees (142 knees in females and 70 knees in males) were available for a short term review. All the included patients were Asian Indians and belonged to middle to high socio-economic class. The inclusion criteria were patients of all BMI (body mass index) presenting with severe varus deformities of the knee, where this technique was used and patients were available for a short term follow up.

Suitable anaesthesia is administered and the procedure is performed under tourniquet. A midline skin incision is made and deepened in layers till the fascia of quadriceps is reached. Medial arthrotomy is performed using the midvastus approach in which the vastusmedialis is dissected through its substance or by a medial para-patellar approach. A sub-periosteal sleeve is elevated over the medial aspect of proximal tibia with a cautery followed by a curved osteotome. Patellaplasty is performed [3]. Bone cuts are taken and cemented tibio-femoral components are inserted.

The arthrotomy closure is done with the knee in extension in the following sequence. Initially a box suture is taken at the superior pole of patella at the junction of the quadriceps with the vastusmedialis. A continuous interlocking suture is taken from the box suture till the proximal division of vastusmedialis. Another box suture is taken at the inferior pole of the patella with the quadriceps tendon. The two box sutures are then connected with continuous interlocking sutures.

Two pairs of holes are drilled over the medial aspect of tibial tuberosity with a 3.2 $\mathrm{mm}$ drill bit (Figure 1, Figure 2).

A towel clamp is used to convert the adjacent pair of holes into a curved tunnel through which a suture needle can pass (Figure 3, Figure 4).

Thus, two tunnels are created on the medial aspect of tibial tuberosity. A No.1 Polyglactin 910 suture with a reverse cutting needle is passed through the medially elevated periosteal sleeve (Figure 5), then into the tunnel (Figure 6) and then through the periosteum along with the patellar tendon on the other side.

Similar suturing is done through the other tunnel and then intermittent suture knots are tied (Figure 7, Figure 8).

Subcutaneous closure is done with interrupted No.1polyglactin suture and then interrupted sub-cuticular sutures are taken with absorbable undyed braided 2 - 0 polyglactin 910 with a reverse cutting needle. 


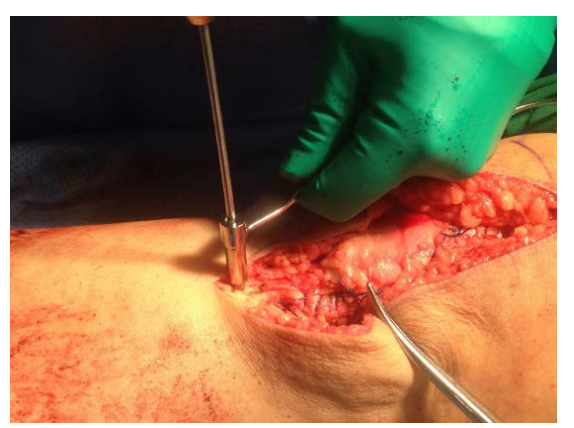

Figure 1. Clinical image of the knee joint during a TKA: Showing a $2.5 \mathrm{~mm}$ drill bit used with a drill sleeve to makes holes over the tibial tuberosity.

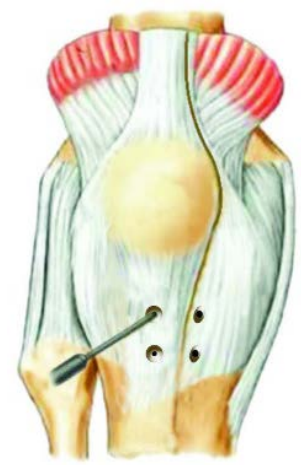

Figure 2. Diagrammatic representation of the knee joint: Showing a drill bit used to make holes over the tibial tuberosity.

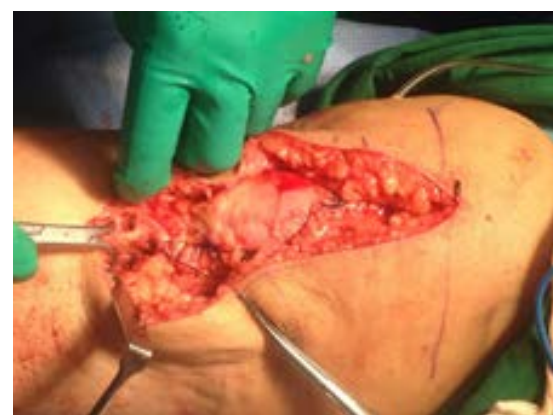

Figure 3. Clinical image of the knee joint during a TKA: Showing a towel clamp used to convert the drill holes into a tunnel.

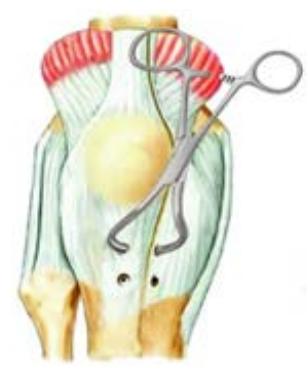

Figure 4. Diagrammatic representation of the knee joint: Showing a towel clamp used to convert the drill holes into a tunnel. 


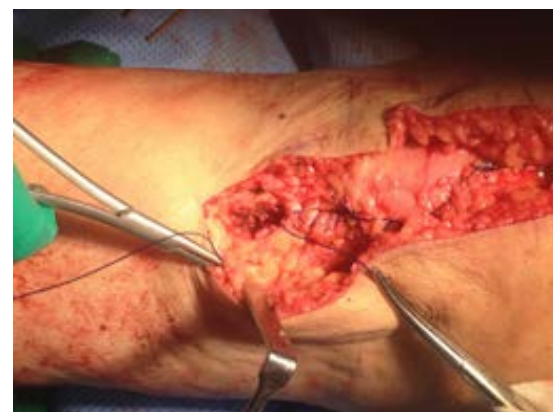

Figure 5. Clinical image of the knee joint during a TKA: Showing a suture needle passing through a medially elevated periosteal sleeve.

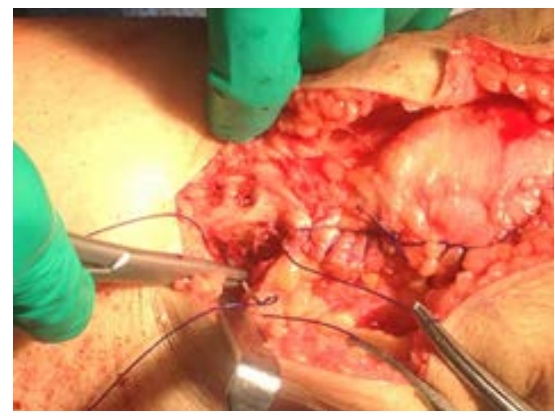

Figure 6. Clinical image of the knee joint during a TKA: Showing suture needle passing through the drilled tunnel.

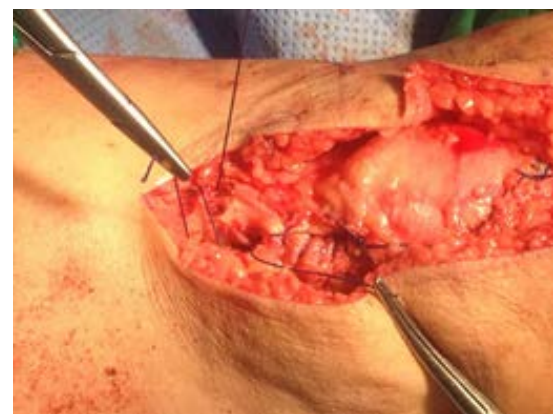

Figure 7. Clinical image of the knee joint during a TKA: Showing the sutures used to take an intermittent knot.

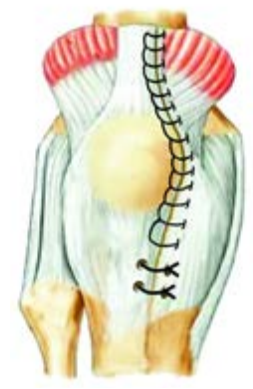

Figure 8. Diagrammatic representation of the knee joint: Showing intermittent knots taken over the medial periosteal sleeve with the patellar tendon. 


\section{Discussion}

Varus deformity of the knee is the most common indication for TKA. Compounding the problem, is the severity of varus deformity at presentation. Due to long standing deformity the medial soft tissue structures like medial capsule, medial collateral ligament and the pes anserinus are contracted and tight. Sub periosteal release corrects the deformity but at the same time increases the space between the tibial tuberosity and medial soft tissues. Passing sutures only through the soft tissues places a lot of stress on the tissues and the sutures tend to cut-out. Hence, the technique of passing sutures through the thick elevated periosteal sleeve into the bone tunnel was applied here. Suture anchors can supplant this technique.

The bone tunnel and suture anchor techniques have their own advantages and disadvantages. The bone tunnel technique is the conventional method which is used since many years in areas like the ankle for ligament repair and for suturing external rotators in hip replacement in posterior approach [4]. This method is stronger, more secure, has remote chances of cut out of sutures without any additional increase in the cost of surgery [5]. Suture anchors are relatively expensive, with chances of pull out of anchors, anchor breakage, metal irritation, sterile inflammation and infection [6]. Bioabsorbable anchors which are a more desirable alternative to metallic fixation are advantageous in that they reduce the complications associated with the use of metal [7]. However, bioabsorbable suture anchors are associated with serous discharge, synovitis and cannot be visualized on radiographs.

Partial avulsion or peeling of the patellar tendon which occurs during eversion of patella [8] can also be sutured using this bone tunnel technique.

An optimal tension closure helps early rehabilitation and recovery [2], reduces chances of patellar subluxation and improves patellar tracking [9].

\section{Conclusion}

We recommend this technique of closure in patients after correction of severe varus deformity or with partial avulsion of the patellar tendon due to patellar eversion during TKA.

\section{Acknowledgements}

None.

\section{References}

[1] Kurtz, S., Ong, K., Lau, E., Mowat, F. and Halpern, M. (2007) Projections of Primary and Revision Hip and Knee Arthroplasty in the United States from 2005 to 2030. Journal of Bone \& Joint Surgery - American Volume, 89, 780-785. https://doi.org/10.2106/00004623-200704000-00012

[2] Kharat, K. (2012) Closure in Knee Replacement Surgery. Journal of Orthopaedic Case Reports, 2, 31-32.

[3] Agarwala, S., Sobti, A. and Naik, S. (2015) Patellaplasty as an Alternative to Replacing Pa- 
tella in Total Knee Arthroplasty. Open Journal of Orthopedics, 5, 277-282.

https://doi.org/10.4236/ojo.2015.59037

[4] Sioen, W., Simon, J.P., Labey, L. and Van Audekercke, R. (2002) Posterior TransosseousCapsulotendinous Repair in Total Hip Arthroplasty: A Cadaver Study. Journal of Bone \& Joint Surgery - American Volume, 84-A, 1793-1798.

https://doi.org/10.2106/00004623-200210000-00009

[5] Li, X., Killie, H., Guerrero, P. and Busconi, B.D. (2009) Anatomical Reconstruction for Chronic Lateral Ankle Instability in the High-Demand Athlete: Functional Outcomes after the Modified Brostrom Repair using Suture Anchors. American Journal of Sports Medicine, 37, 488-494. https://doi.org/10.1177/0363546508327541

[6] Hu, C.-Y., Lee, K.-B., Song, E.-K., Kim, M.-S. and Park, K.-S. (2013) Comparison of Bone Tunnel and Suture Anchor Techniques in the Modified Brostrom Procedure for Chronic Lateral Ankle Instability. American Journal of Sports Medicine, 41, 1877-1884.

https://doi.org/10.1177/0363546513490647

[7] Kim, M.K., Na, S.I., Lee, J.M. and Park, J.Y. (2014) Comparison of Bioabsorbable Suture Anchor Fixation on the Tibial Side for Anterior Cruciate Ligament Reconstruction using Free Soft Tissue Graft: Experimental Laboratory Study on Porcine Bone. Yonsei Medical Journal, 55, 760-765. https://doi.org/10.3349/ymj.2014.55.3.760

[8] Ryan, J.A., Meyers, K.N., DiBenedetto, P., Wright, T.M. and Haas, S.B. (2010) Failure of the Patellar Tendon with the Patella Everted Versus Noneverted in a Matched-Pair Cadaver Model. HSS Journal, 6, 134-137. https://doi.org/10.1007/s11420-009-9149-0

[9] Plate, J.F., Seyler, T.M., Halvorson, J.J., Santago 2 ${ }^{\text {nd }}$, A.C. and Lang, J.E. (2014) Non-Anatomical Capsular Closure of a Standard Parapatellar Knee Arthrotomy Leads to Patellar Maltracking and Decreased Range of Motion: A Cadaver Study. Knee Surgery, Sports Traumatology, Arthroscopy, 22, 543-549. https://doi.org/10.1007/s00167-013-2369-3

\section{Submit or recommend next manuscript to SCIRP and we will provide best service for you:}

Accepting pre-submission inquiries through Email, Facebook, LinkedIn, Twitter, etc.

A wide selection of journals (inclusive of 9 subjects, more than 200 journals)

Providing 24-hour high-quality service

User-friendly online submission system

Fair and swift peer-review system

Efficient typesetting and proofreading procedure

Display of the result of downloads and visits, as well as the number of cited articles

Maximum dissemination of your research work

Submit your manuscript at: http://papersubmission.scirp.org/

Or contact ojo@scirp.org 